\title{
A fotografia artística e as tecnologias digitais como prática na Educação de Jovens e Adultos em tempos de COVID-1 9
}

\author{
Artistic photography and digital technologies as practice in the \\ Education of Young people and Adults in the COVID-19 period
}

\section{La fotografía artística y las tecnologías digitales como práctica en la Educación de Jóvenes y Adultos en tiempos de COVID-I 9}

\author{
Nubia Carla Ferreira Cabau' \\ https://orcid.org/0000-0002-8179-4898 \\ Patrícia Lakchmi Leite Mertzig² \\ https://orcid.org/0000-0002-1793-004X \\ Maria Luisa Furlan Costa ${ }^{3}$ \\ https://orcid.org/0000-0002-4286-5892
}

\begin{abstract}
Resumo: $O$ presente texto se configura como um relato experiência ocorrido com uma turma da Educação de Jovens e Adultos (EJA), na disciplina de Arte, que envolveu conteúdos de Fotografia. A metodologia utilizada foi a Unidade Didática. Esta foi dividida em quatro etapas: apresentação da situação, produção inicial, módulos ou oficinas e produção final. As aulas foram desenvolvidas em quatro turmas de EJA, séries iniciais, e contaram com 10 alunos por turma, totalizando o número de 40 alunos, com faixa etária entre 16 e 40 anos. A experiência ocorreu em contexto presencial, mas, por utilizar as Tecnologias da Informação e Comunicação (TICs), é possível realizá-lo no contexto atual do ensino remoto emergencial. Concluímos que a aprendizagem foi significativa aos estudantes e as mídias utilizadas contribuíram para ampliar o acesso às tecnologias digitais. Observamos a necessidade de a Educação Básica incluir de maneira mais consistente as TICs no cotidiano escolar, bem como fomentar esse conteúdo em cursos de formação de professores.
\end{abstract}

Palavras-chave: Educação básica. Ensino de artes. Tecnologias digitais.

\footnotetext{
Mestra em Educação pela Universidade Estadual de Maringá (UEM). Professora na Secretaria de Estado de Educação do Paraná. E-mail: nubiacabau@gmail,com

${ }^{2}$ Doutora em Educação Pela Universidade Estadual de Maringá (UEM). Professora no Departamento de Educação da Universidade Estadual de Londrina (UEL). E-mail: patriciamertzig@gmail.com

${ }^{3}$ Doutora em Educação pela Universidade Estadual Paulista Júlio de Mesquita Filho (Unesp). Professora associada da Universidade Estadual de Maringá (UEM). E-mail: luisafurlancosta@gmail.com
}

Olhar de professor, Ponta Grossa, v. 24, p. I-8, e-16093.050, 202I.

Disponível em <https://revistas2.uepg.br/index.php/olhardeprofessor> 
Abstract: This text is an experience report resulting from the work with a group of Youth and Adult Education (EJA), in the discipline of Art that involved Photography contents. The methodology used was the Teaching Unit, which was divided into four stages: Presentation of the situation, Initial Production, Modules or Workshops and Final Production. The lessons were taught in four EJA classes of the initial years that had I 0 students each, totaling 40 students aged between 16 and 40 years. The experience took place in the face-to-face context, but for using ICTs, it is possible to use the same material in the current context of emergency remote education. We concluded that learning was significant for students and the media used contributed to expand their access to digital technologies. We observed the need for the Basic Education to include ICTs in a more consistent manner in the school daily life, as well as to encourage this content in teacher training courses.

Keywords: Basic education. Art education. Digital technologies.

Resumen: Este texto está configurado como un relato de experiencia con un grupo de Educación de Jóvenes y Adultos (EJA), en la asignatura de Arte que involucró contenidos de Fotografía. La metodología utilizada fue la Unidad Didáctica. Esta se dividió en cuatro etapas: presentación de la situación, producción inicial, módulos o talleres y producción final. Las clases se desarrollaron en cuatro grupos del EJA, series iniciales y con 10 estudiantes por clase, con un total de 40 estudiantes entre 16 y 40 años. La experiencia tuvo lugar en el contexto cara a cara pero, mediante el uso de las TIC, es posible hacerlo en el contexto actual de la educación remota de emergencia. Llegamos a la conclusión de que el aprendizaje ha sido significativo para los estudiantes y los medios utilizados contribuyeron a ampliar el acceso a las tecnologías digitales. Observamos la necesidad de que la Educación Básica incluya las TIC de una manera más contundente en la vida diaria de la escuela, así como para fomentar este contenido en los cursos de formación de docentes.

Palabras-clave: Educación básica. Educación artística. Tecnologías digitales.

\section{Introdução}

Na segunda metade de 2019, algo no mundo começou a mudar. Em Wuhan, na China, surgiu o primeiro caso de uma doença respiratória causada pelo novo coronavírus, uma síndrome respiratória aguda grave. O que foi, inicialmente, até negado e que parecia ser um problema local, adquiriu proporções mundiais, culminando com a declaração da Organização Mundial da Saúde (OMS), em II de março de 2020, de que se tratava de uma pandemia.

De lá para cá tudo foi alterado. Fronteiras geográficas se fecharam, barreiras sanitárias foram instituídas, medidas de higiene aumentadas e, por fim, o isolamento social foi indicado como a melhor forma de prevenção do contágio e contaminação do vírus.

Tais medidas impactaram a sociedade de forma profunda e as mudanças instituídas fizeram com que novos contextos fossem organizados, mudando radicalmente nossas vidas. Dentre tais mudanças, está a suspensão das atividades acadêmicas, em todos os níveis, no modelo presencial, o que exigiu dos profissionais da educação novas formas de ser e pensar a sala de aula.

Para além da pandemia da COVID-19, estamos vivendo, desde o início do século XXI, na era das Tecnologias da Informação e Comunicação (TICs), sendo impossível dissociar a educação dos novos saberes exigidos por esta sociedade conhecida como Sociedade da Informação. De acordo com Moran (20I2), as competências digitais são essenciais para o desenvolvimento de uma educação plena e, atualmente, um aluno sem o domínio digital perde importantes chances de se inserir no contexto contemporâneo. 
Desta forma, é papel do professor selecionar e utilizar as tecnologias para reconfigurar sua prática pedagógica, expandido as fronteiras espaço-temporais das salas de aula, estabelecendo novas relações aos novos espaços de saber, fazendo da aprendizagem um momento colaborativo e de efetiva transformação.

A escolarização perpassa o desenvolvimento de um cidadão ético, crítico e conhecedor de sua realidade. Assim, destacamos que as linguagens artísticas, enquanto conteúdo escolar, propiciam a promoção desses conceitos por intermédio da reflexão, pois, para criar, é preciso o trinômio ação/reflexão/ação. Desenvolver no aluno o olhar crítico e a capacidade de interpretar o mundo que o cerca é papel fundamental da escola e, portanto, é também das artes quando inseridas neste contexto.

Barbosa (20II) aponta a necessidade de que alunos se tornem aptos para entender a arte "na condição pós-moderna contemporânea." A autora acrescenta que apenas a ação inteligente do professor pode desenvolver no aluno o "comportamento de cidadão fruidor de cultura e conhecedor de sua própria nação" (BARBOSA, 201 I, p. 14).

O ambiente escolar é também o locus de inovação e de inclusão aos alunos que, por fatores econômicos e sociais, são excluídos digitalmente. Favorecer, portanto, o acesso à informação por meio das tecnologias é uma maneira de incluir digitalmente, além de capacitar para o uso das novas mídias, podendo tornar o processo de ensino e aprendizagem mais dinâmico e inovador.

Sendo assim, ao propor o trabalho com alunos da Educação de Jovens e Adultos (EJA), observamos a necessidade de desenvolver, por intermédio das artes, o conceito de fotografia artística no contexto contemporâneo, utilizando as novas tecnologias, como tablets, celulares e computadores, a fim de que o aluno entenda e se aproprie desta linguagem - a fotografia - como ferramenta de expressão artística, política e social. Dessa forma, o presente texto se configura como um relato de experiência ocorrido com uma turma da EJA, na disciplina de Arte, que envolveu conteúdos de Fotografia.

Para tanto, a metodologia elencada é a Unidade Didática. Segundo Dolz, Noverraz e Schneuwly (2004), a Unidade Didática é dividida em etapas e componentes. As etapas são divididas em quatro: apresentação da situação, produção inicial, módulos ou oficinas e produção final. Quanto aos componentes, a Unidade Didática deve iniciar com a contextualização, ou seja, a apresentação de uma situação- problema que deverá levar à reflexão e à percepção dos saberes que cada indivíduo traz consigo sobre o tema.

Assim, a Unidade Didática foi desenvolvida em 12 aulas de Artes, na modalidade Educação Especial, para alunos da Educação de Jovens e Adultos em escola especializada da Rede Estadual do Paraná, com conteúdos e etapas ligados entre si, organizados de acordo com o tema proposto, sendo que as atividades foram planejadas com a intenção de atingir os objetivos estabelecidos no projeto.

Olhar de professor, Ponta Grossa, v. 24, p. I-8, e-16093.050, 2021.

Disponível em <https://revistas2.uepg.br/index.php/olhardeprofessor> 
A fotografia artística e as tecnologias digitais como prática na Educação de Jovens e Adultos em tempos de COVID-19

Acreditamos ser importante destacar que a quantidade de aulas veio ao encontro das necessidades especiais de cada aluno, que, como prevê a legislação vigente, garante atenção individualizada, apoio e suporte permanente em virtude de sua deficiência, respeitando seu tempo e ritmo próprio de aprendizagem.

As aulas foram aplicadas para 4 turmas de EJA, séries iniciais que, por se tratar de educação especial, têm, em sua constituição, um número reduzido de alunos, contando com uma média de 10 alunos por turma, totalizando o número de 40 alunos, com faixa etária entre 16 e 40 anos. Consideramos que o projeto pode ser desenvolvido para pessoas com ou sem deficiências, já que as adaptações utilizadas referiram-se unicamente a flexibilizações temporais na forma de abordagem dos conteúdos apresentados. Destacamos, ainda, que o relato a seguir ocorreu em contexto presencial, mas, por utilizar as TICs, é possível realizá-lo no contexto atual do ensino remoto emergencial.

\section{Desenvolvimento}

Seguindo os passos e procedimentos para uma sequência didática, o primeiro momento configurou-se em uma contextualização histórica, apresentando aos alunos uma breve história da fotografia, dentro do entendimento de arte contemporânea, e as novas maneiras artísticas de se transmitir uma mensagem utilizando-se a fotografia. Por se tratarem de alunos adultos, foi importante ouvir o que cada um tinha a dizer sobre o tema, percebendo as vivências trazidas por meio do contexto social em que estão inseridos e também dos saberes empíricos, fruto da relação homem/meio, além das transformações ocorridas na fotografia e nas TICs nas últimas décadas. Lembramos que foi no final do século $X I X$ e início do século $X X$ que a arte rompeu com a forma figurativa para se embrenhar em experiências que integram o representativo.

Nesse contexto, foi possível resgatar fatos históricos para situar os alunos sobre a posição do artista (que nunca é passiva) frente às transformações que, historicamente, modificam a humanidade. Falar sobre as câmeras fotográficas de antigamente, as câmeras digitais atuais (destacando as câmeras digitais dos smartphones) e como as imagens são produzidas em cada uma dessas câmeras foi igualmente importante. Este foi um momento de trocas mútuas, em que os estudantes participaram ativamente, contando suas vivências, relembrando o uso das máquinas fotográficas analógicas, dos filmes, do processo de revelação fotográfica; inclusive, na aula seguinte, um aluno trouxe uma máquina fotográfica de sua casa e alguns negativos para compartilhar com a turma.

A segunda etapa de uma Unidade Didática é a produção inicial, que se configura como um diagnóstico do conhecimento prévio que o participante tem sobre o conteúdo. De acordo com Martiniano (2015), considerar o aluno como agente ativo no conhecimento de sua realidade implica na

Olhar de professor, Ponta Grossa, v. 24, p. I-8, e-16093.050, 2021.

Disponível em <https://revistas2.uepg.br/index.php/olhardeprofessor> 
possibilidade de o mesmo adquirir os conhecimentos necessários para a modificação de sua própria realidade. Como afirma Saviani (2008, p. 52):

[...] identificando os problemas, se apropriando de instrumentos teóricos e práticos necessários para a resolução do problema encontrado na prática social, permitindo ao estudante perceber que é capaz de transformar a realidade que o cerca, mediante a apropriação de elementos culturais indispensáveis, a compreensão e apreensão do mundo, confirmando ou rejeitando as hipóteses e, por fim, chegar à síntese, ou seja, a apropriação do conhecimento sistematizado, gerador de desenvolvimento.

Desta forma, ao identificar os saberes que os alunos traziam consigo sobre o assunto, foi possível apresentar a proposta de trabalho e, juntamente com eles, determinar a forma de desenvolvimento das aulas e das atividades, bem como apresentar os objetivos e estabelecer os critérios de avaliação.

A terceira etapa de uma Unidade Didática é a organização de módulos ou oficinas para o desenvolvimento dos conteúdos elencados na produção inicial. Seu componente é a realização, onde os participantes: "[...] se propõem a pensar a partir dos conteúdos, utilizando os conhecimentos adquiridos para estabelecer, em conjunto com os seus pares, possíveis soluções aos problemas identificados" (DOLZ; NOVERRAZ; SCHNEUWLY, 2004 apud PARANÁ, 2019, p.18).

Esta terceira etapa pode ainda ser desenvolvida em vários módulos ou oficinas, portanto, após apresentar conceitos sobre imagem, proporção, equilíbrio e estudo da biografia de Sebastião Salgado (renomado fotógrafo brasileiro) e, fundamentando-se em Barbosa (20I I) e sua relação dialógica entre Ler, Fazer e Contextualizar do fazer artístico, buscamos desenvolver a visão contemporânea do ensino da arte que valoriza a construção e a elaboração como procedimento artístico por meio da experimentação. $O$ momento de experimentação configura-se em um importante período, onde o lócus da ação, bem como os conceitos estudados poderão se materializar por meio de um trabalho prático, quando o aluno deverá associar a teoria ao contexto e à prática, observando o que, de fato, ficou assimilado e o que ainda precisa de maior aprofundamento.

Nesse momento, os alunos elegeram um tema para suas fotografias e, utilizando o espaço escolar, iniciaram o trabalho prático de fotografar aplicando as competências desenvolvidas nas aulas anteriores. O conceito de competência adotado pela Base Nacional Comum Curricular (BNCC) é definido como "[...] como a mobilização de conhecimentos (conceitos e procedimentos), habilidades (práticas, cognitivas e socioemocionais), atitudes e valores para resolver demandas complexas da vida cotidiana, do pleno exercício da cidadania e do mundo do trabalho" (BRASIL, 2017, p. 8).

As novas habilidades e competências se diferenciam dos atuais processos de ensino e aprendizagem e, nesse sentido, as novas relações de aprendizagem por meio das tecnologias ganham

Olhar de professor, Ponta Grossa, v. 24, p. I-8, e-16093.050, 2021.

Disponível em <https://revistas2.uepg.br/index.php/olhardeprofessor> 
A fotografia artística e as tecnologias digitais como prática na Educação de Jovens e Adultos em tempos de COVID-19 espaço expressivo entre as 10 competências gerais. Como exemplo, podemos citar a competência 5 da BNCC, que, ao tratar das tecnologias, aponta para a capacidade de:

[...] compreender, utilizar e criar tecnologias digitais de informação e comunicação de forma crítica, significativa, reflexiva e ética nas diversas práticas sociais (incluindo as escolares) para se comunicar, acessar e disseminar informações, produzir conhecimentos, definir problemas e exercer protagonismo e autoria na vida pessoal e coletiva (BRASIL, 2017, p. 9).

Desta forma, após o trabalho prático de fotografar, os alunos foram levados ao laboratório de informática, onde a professora apresentou o software de edição de imagens do Sistema Operacional Windows e seus principais recursos. A prioridade foi para os recursos de edição, como, por exemplo, enquadramento e proporção, e também de ajustes, tais como luz, cor e brilho, já que estes foram os conteúdos discutidos e apresentados durante o desenvolvimento das aulas anteriores.

Este trabalho foi realizado individualmente, ou seja, cada aluno teve a oportunidade de fazer sua própria criação e edição de imagens usando os recursos tecnológicos disponíveis. Este foi o momento de oferecer ao aluno a oportunidade de contato com as tecnologias para que ele explorasse, na prática, os diferentes recursos tecnológicos, de forma que estes contribuíssem para a promoção da efetiva aprendizagem. Foi um momento de muita participação de toda a turma. Devido às condições sociais e econômicas, muitos alunos nunca haviam tido acesso, até então, ao uso de uma máquina digital ou tratamento de imagem utilizando software de edição. Podemos afirmar, assim, que todos os alunos gostaram muito da experiência, a qual os levou a um grande aprendizado.

Como trabalho final, a professora sugeriu a organização de uma exposição fotográfica, que serviu de subsídio para a avaliação de todo o processo de aprendizagem, já que, por meio da realização do trabalho prático, foi possível identificar possíveis dificuldades, bem como se os alunos tiveram real aquisição de conhecimentos, a fim de desenvolver o projeto de uma fotografia artística segundo os objetivos propostos.

A metodologia de sequência didática, etapa da produção final, trata-se da possibilidade de superar e colocar os problemas em prática, além de configurar um subsídio para "avaliação do processo e identificação de possíveis dificuldades que ainda devem ser superadas" (DOLZ; NOVERRAZ; SCHNEUWLY, 2004 apud PARANÁ, 2019, p. 17).

Este também foi um momento relevante do processo. Os alunos organizaram a exposição, que movimentou toda a escola. Por não haver condições financeiras para imprimir as fotos, optou-se por uma apresentação em Power Point, em que cada aluno exibiu suas fotos, explicando sobre o tema escolhido e esclarecendo sobre como foi seu processo criativo.

Olhar de professor, Ponta Grossa, v. 24, p. I-8, e-16093.050, 202 I.

Disponível em <https://revistas2.uepg.br/index.php/olhardeprofessor> 


\section{Considerações finais}

Ao desenvolver esta Unidade Didática, o objetivo principal foi o de produzir fotos artísticas por meio de recursos tecnológicos disponíveis em máquinas digitais, tablets e em smartphones. Ficou evidente que a forma como as aulas foram conduzidas propiciou aos alunos um aprendizado significativo, não somente no conteúdo abordado, mas no uso das tecnologias.

Em tempos de pandemia, podemos observar, por meio da prática diária em sala de aula, que professores e alunos estão vivendo um momento único da educação, e que muitos estão críticos e reticentes quanto ao novo formato. Muitos são os pontos que podem se levantar sobre o tema, mas o que fica evidente é que ao menos uma questão é indiscutível: o professor precisa "aprender a ensinar" utilizando as tecnologias e os alunos precisam "aprender a aprender" utilizando-as.

Tais questões perpassam a formação de professores, já que não é possível exigir do profissional aquilo que ele não aprendeu, e o que vemos no momento atual é exatamente isso: muitos professores nunca usaram ou tiveram, em suas formações (iniciais ou continuadas), métodos de ensino ou estratégias de aprendizagem por meio das TICs.

Esse fato pode ser comprovado pela prática diária no ambiente escolar, em que vemos professores necessitando de apoio direto e orientação para que se efetive a aplicação de aulas remotas. Na rede estadual do estado do Paraná, as aulas estão sendo desenvolvidas via Google ClassRoom, aplicativo que faz parte do G Suits for Education: "[...] é um conjunto de apps gratuitos do Google feito sob medida para as escolas que oferece vantagens como segurança integrada com várias camadas e suporte 24 horas por dia, 7 dias por semana, sem custo extra"4.

Desta forma, acreditamos que é possível transferir o conteúdo abordado na proposta de sequência didática para o ambiente do Google ClasssRoom, uma vez que, neste espaço, as interações podem se dar via Google Meet, além da possibilidade de compartilhar e interagir com os alunos textos, vídeos e áudios nos murais e atividades. O que podemos afirmar é que, com formação adequada, o professor se sentirá apto e seguro para utilizar as ferramentas tecnológicas que o momento exige e observar que o aprendizado pode acontecer de forma mais gratificante. Porém, essa formação é extremamente necessária.

Nesse contexto, a Unidade Didática apresenta-se como uma das formas possíveis de educação em tempos de pandemia, haja vista que tudo o que foi exposto pode ser feito de forma remota, a distância, com professores e alunos conectados via internet ou em ambientes virtuais de aprendizagem.

\footnotetext{
${ }_{4}^{4}$ Disponível em: <https://edu.google.com/intl/pt-BR_ALL/products/gsuite-for-education/?modal_active=none>. Acesso em: 15 jun. 2020.
} 
A fotografia artística e as tecnologias digitais como prática na Educação de Jovens e Adultos em tempos de COVID-19

Para além destas questões, fica a observação de que os alunos apreciam as tecnologias e que cabe à escola proporcionar-Ihes efetivas formas de aprendizagem, utilizando as TICs, cumprindo, assim, o seu papel social de inclusão, de formação e de preparação para a vida.

\section{Referências}

BARBOSA, A. M. Inquietações e Mudanças no Ensino da Arte. São Paulo: Cortez, 20 I I.

BRASIL. Ministério da Educação. Base Nacional Comum Curricular. Educação é a base. Brasília: MEC/CONSED/UNDIME, 2017. Disponível em: <http://basenacionalcomum.mec.gov.br/.> Acesso em: I 4 jun. 2020.

DOLZ, J.; NOVERRAZ, M.; SCHNEUWLY, B. Sequências Didáticas para o Oral e a Escrita: Apresentação de um Procedimento. In: SCHNEUWLY, B; DOLZ, J. Gêneros orais escritos na escola. São Paulo: Mercado de Letras, 2004. p. 95-I28.

MARTINIANO, E. Sequência Didática: o ambiente virtual de aprendizagem como um recurso metodológico para um ensino interativo. Londrina: UTFPR, 2015. Disponível em: http://repositorio.utfpr.edu.br/jspui/bitstream/I//393/2/LD_PPGEN_M_Martiniano\%2C\%20Eziquiel_2 015_I.pdf. Acesso em: I4 jun. 2020.

MORAN, J. M. A Educação que Desejamos: novos desafios e como chegar lá. 5. ed. Campinas, SP: Papirus, 2012.

PARANÁ - SEED. PDE Programa de Desenvolvimento Educacional. Caderno de Orientações. 2019.

SAVIANI, D. Escola e Democracia. Campinas: Autores Associados, 2008.

Recebido em: 15 de junho de 2021.

Versão corrigida recebida em: 03 de novembro de 2020.

Aceito em: 03 de novembro de 2020.

Publicado online em: 28 de maio de 202I.

Olhar de professor, Ponta Grossa, v. 24, p. I-8, e-I6093.050, 202I.

Disponível em <https://revistas2.uepg.br/index.php/olhardeprofessor> 